\title{
Relações entre leitura, escrita e alfabetização/letramento científico: um levantamento bibliográfico em periódicos nacionais da área de ensino de ciências
}

\author{
Relations between reading, writing and scientific literacy: \\ a bibliographical survey of Brazilian periodicals \\ of science education
}

Carolina Suisso $^{1}$. Tatiana Galieta ${ }^{1}$

\begin{abstract}
Resumo: $\mathrm{O}$ artigo busca averiguar as relações estabelecidas entre leitura/escrita e alfabetização científica (AC) e/ou letramento científico (LC) em textos de periódicos brasileiros de Educação em Ciências. Em levantamento bibliográfico, localizamos 21 artigos que abordam a leitura e/ou a escrita em uma perspectiva de AC/LC, embora somente três deles tenham esta relação como escopo. As publicações estabelecem vínculos superficiais considerando a associação entre a aprendizagem de Ciências e de leitura/escrita na língua materna, e não a questão da especificidade da aprendizagem da leitura/escrita nas Ciências. A análise dos artigos em que escrita e/ou leitura são objetos empíricos indica um possível pressuposto comum: a habilidade de ler/escrever quando o conteúdo é científico difere da habilidade de ler/escrever outros temas. Indicamos a necessidade de que as pesquisas sejam rigorosas no delineamento dos referenciais teóricos e dos conceitos envolvidos, contribuindo efetivamente para a compreensão daquelas relações, visando à melhoria do Ensino de Ciências.
\end{abstract}

Palavras-chave: Letramento científico. Alfabetização científica. Escrita. Leitura. Educação em ciências.

\begin{abstract}
This paper aims to investigate relationships that are established between reading/writing and scientific literacy (SL) in the texts of Brazilian journals of Science Education. Bibliographical survey found 21 papers that address the reading and/or writing from the perspective of SL, although only three of them have this relationship as their focus. The publications provide superficial links considering the association between learning science and reading/writing in the native language and not the question of the specificity of learning to read/write in the sciences. The analysis of articles in which writing and/or reading are empirical objects indicates a possible common assumption: the ability to read/write when content is scientific is different from the ability to read/write other topics. The study indicates the need for rigorous researches into the design of theoretical frameworks and the concepts involved, in order to contribute effectively to the understanding of those relationships, aiming at to improve the science teaching.
\end{abstract}

Keywords: Scientific literacy. Writing. Reading. Bibliographical survey. Science education.

\footnotetext{
${ }^{1}$ Programa de Pós-Graduação em Educação em Ciências e Saúde, Núcleo de Tecnologia Educacional para a Saúde (NUTES), Universidade Federal do Rio de Janeiro (UFRJ), Av. Carlos Chagas Filho, 373, Bloco A, sala 12, Cidade Universitária, CEP 21949-902, Rio de Janeiro, RJ, Brasil. E-mail: <suisso@ig.com.br>.
} 


\section{Introdução}

As expressões letramento científico (LC) e alfabetização científica (AC) vêm sendo amplamente utilizadas nos mais variados contextos. Segundo Martins (2010, p. 364)

$\mathrm{Na}$ literatura, encontramos relatos de investigações científicas e intervenções voltadas à promoção da alfabetização científica, que a significam como objetivo de ensino, meta de aprendizagem, referencial para desenvolvimento de currículos, base para avaliação do conhecimento público da ciência ou como objeto de pesquisa. Discute-se o tema da alfabetização/letramento científico no contexto das políticas públicas, questiona-se a pertinência e os sentidos dos termos alfabetização e letramento nas pesquisas do campo, e busca-se explicitar seus aspectos históricos, políticos e epistemológicos.

As expressões AC e LC, de acordo com Cachapuz et al. (2008), remetem-se ao seu equivalente em inglês scientific/science literacy (SL) inicialmente usado, no final dos anos $1950 \mathrm{e}$ início dos anos 1960, para chamar atenção à necessidade de se especificar um currículo apropriado de Ciências para os estudantes que não planejavam prosseguir na carreira científica. Apesar do conceito de SL vir sendo utilizado cada vez mais extensivamente em vários países, é de conhecimento da comunidade científica que não existe consenso a respeito de sua definição (ROBERTS, 2007).

Ainda, segundo citações de Roberts (2007), autores como Agin (1974), Bybee (1995), Jenkins (1997), Millar (1996), Pella et al. (1966), Ryder (2001), Shamos (1995), Shen (1975) e Sjøberg (1997) estabeleceram níveis, tipos ou dimensões para SL na intenção de definir o termo. Para ele, a infinidade de definições e conceitos relacionados à SL pode ser melhor compreendida se forem observadas as duas fontes curriculares (legítimas, mas conflitantes) do ensino de Ciências: (1) os assuntos científicos em si, as questões essencialmente científicas; e (2) as situações em que a Ciência pode desempenhar um papel, participar em assuntos humanos de outra natureza, que não essencialmente científica. Para o autor, por meio de uma análise da literatura sobre SL é perceptível que existem extremos em defesa dessas duas fontes, resultando em duas categorias de análise - visão 1 e visão 2 - que representam os extremos de um continumm. A visão 1 dá sentido à SL por meio dos produtos e processos da própria Ciência, enquanto a visão 2 significa SL por meio de situações que possuem componentes de diversas ordens, que não apenas a científica, e podem ser enfrentadas pelos alunos como cidadãos. Historicamente, a visão 1 teria sido o ponto de partida para a definição de SL, no entanto, um número crescente de vozes tem enfatizado a importância das situações do mundo real (visão 2) como ponto de partida para, então, chegar nas questões da Ciência e constatar o que é relevante.

\footnotetext{
${ }^{2}$ A sigla SL será aqui utilizada sempre que fizer referência ao termo scientific literacy encontrado em textos originais em inglês.
} 
Santos (2007) faz uma diferenciação das expressões alfabetização científica e letramento científico (ambas utilizadas na literatura como traduções do termo em inglês, scientific literacy). Para ele, o termo alfabetização científica estaria relacionado a um processo mais elementar no ensino de Ciências, que inclui: o reconhecimento de alguns de seus vocábulos, a memorização de fórmulas e a resoluções de algoritmos; enquanto o termo letramento científico estaria associado à prática social do ensino de Ciências (SANTOS, 2007, p. 479).

Neste artigo, adota-se a diferenciação entre alfabetização e letramento, pois na tradição escolar a alfabetização científica tem sido considerada na acepção do domínio da linguagem científica, enquanto o letramento científico, no sentido do uso da prática social, parece ser um mito distante da prática de sala de aula. Ao empregar o termo letramento, busca-se enfatizar a função social da educação científica contrapondo-se ao restrito significado de alfabetização escolar.

Fazendo uma comparação entre os trabalhos de Roberts (2007) e Santos (2007), podemos encontrar semelhanças entre aquilo que o primeiro chamou de "Visão 1" e "Visão 2" e o que o segundo chamou de "alfabetização científica" e "letramento científico", respectivamente.

Norris e Phillips (2003), por sua vez, discutem como os objetivos do ensino de Ciências, muitas vezes, são expressos com o uso do termo literacy, e que tal termo pode assumir dois sentidos na língua inglesa - pode significar a habilidade de ler e escrever e, também, cognoscibilidade, aprendizagem, educação. Segundo os autores, quando nos voltamos para um corpo disciplinado de conhecimento, tal como a Ciência ocidental, a relação entre cognoscibilidade e habilidade de ler e escrever é estreita. Para Norris e Phillips (2003), a capacidade de ler e escrever quando o conteúdo é científico seria o sentido fundamental do SL; e que ser conhecedor, culto e educado em Ciências seria o sentido derivado.

Nesse sentido, Mortimer (1998) apresenta algumas particularidades da linguagem científica em relação à linguagem cotidiana (tais como estruturalidade, nominalização e ausência de sujeito), e discute sua influência no discurso científico escolar. Para ele, reconhecer essas particularidades implica admitir que a aprendizagem das Ciências é inseparável da aprendizagem da linguagem científica. Teixeira (2011) também vincula de alguma maneira o ensino de Ciências com a linguagem, ao tecer reflexões sobre o que é a "alfabetização científica" e sobre a origem da expressão. A autora argumenta que tal expressão estabelece vínculos entre Ciência e leitura -escrita, diz respeito a tudo que envolver escrita/leitura de textos científicos e relaciona-se com a alfabetização na própria língua.

Se observada de forma superficial, a questão da linguagem e da escrita científica na AC/LC seria um produto da própria Ciência intrínseca a ela e, portanto, estaria mais relacionada à "visão 1" proposta por Roberts (2007). No entanto, um olhar social sobre a questão da linguagem pode nos levar a pensar numa relação entre a linguagem e a escrita nas Ciências e uma "visão 2".

Dessa forma, Tfouni (1986, p. 193) afirma que a escrita é "um produto social que surge em decorrência de mudanças nas relações de produção e do aparecimento de novas necessidades de mediações entre o homem e o meio ambiente".

Orlandi (1999, p. 7 apud OLIVEIRA, 2001, p. 33) também associa a escrita às relações sociais: 
[...] a escrita numa sociedade de escrita, não é só instrumento, ela é estruturante. Isso significa que ela é lugar de constituição de relações sociais, isto é, de relações que dão uma configuração específica à formação social e aos seus membros. A forma da sociedade está assim diretamente relacionada com a existência ou a ausência da escrita.

O papel da escrita como estruturante pode então ser discutido no contexto da construção social do conhecimento científico. Tomio (2009), ao discorrer sobre a escrita na produção da Ciência, em seu artigo, cita o livro "Os cientistas precisam escrever" de Barras (1979 apud TOMIO, 2009, p. 6), e argumenta que, para o autor da obra,

[...] o sujeito do conhecimento (pesquisador/cientista) escreve para si (notas de laboratório ou de campo, diários, ideias, lembretes, registros pessoais etc.), escreve para apreender o pensamento e, ao mesmo tempo, elaborá-lo. Além disso, o sujeito escreve para o outro (ensaios, artigos científicos, relatórios etc.), pois na produção do conhecimento científico, também, implica sua comunicação e debate pelos coletivos de pensamento. Nessa perspectiva, na atividade de pesquisar, escrever é parte integrante e essas são tarefas interdependentes no fazer ciência. (Grifos da autora)

Conforme citado anteriormente, de maneira semelhante a Barras (1979 apud TOMIO, 2009, p. 6), Norris e Philips (2003) argumentam que nada do que conhecemos hoje como Ciência ocidental seria possível sem o texto e que, por isso, uma pessoa que não sabe ler e escrever estaria profundamente limitada na aprendizagem sobre Ciências. Podemos associar essa relação intrínseca entre Ciência e linguagem à afirmação de Orlandi (1999 apud OLIVEIRA, 2001, p. 53): "a escrita é um trabalho da memória que estrutura as relações sociais, assim não adianta só aprender a escrever (ou melhor, transcrever), mas inscrever o sujeito na estrutura social (ou melhor, identificar)". Podemos entender, portanto, que ensinar Ciências é inscrever o sujeito em uma estrutura social - a da Ciência escolar - e que, para isso, deve-se levar em conta que tal estrutura está fortemente influenciada pelo aspecto fundamental da escrita nas Ciências e, portanto, pela linguagem científica escolar. Em outras palavras, para se inscrever na estrutura social da Ciência escolar, o sujeito precisa dominar a leitura e a escrita científica escolar. E essa perspectiva se relaciona com a ideia de sentido fundamental do SL de Norris e Philips (2003).

Em trabalho anterior (FERREIRA; GALIETA, 2014), realizamos um levantamento, em periódicos brasileiros da área de Educação em Ciências, buscando verificar a ocorrência do tema leitura/escrita nas pesquisas sobre alfabetização científica (AC) ou letramento científico (LC), identificando suas temáticas e abordagens téorico-metodológicas. No presente artigo, temos como objetivo averiguar que relações os autores dos trabalhos resultantes desse levantamento realizam entre leitura/escrita e AC/LC e, dessa forma, entender como a relação leitura-escrita-LC vem sendo significada no Brasil, já que consideramos que há uma estreita relação entre os conceitos de AC/LC e os processos de leitura/escrita. Entendemos que tais relações devam ser investigadas e discutidas, justamente para que os processos de leitura e escrita nas aulas de ciências sejam aprimorados. A seguir, delineamos as bases metodológicas da pesquisa. 


\section{Considerações metodológicas}

No trabalho de levantamento bibliográfico realizado (FERREIRA; GALIETA, 2014), foram selecionados periódicos brasileiros editados prioritariamente em língua portuguesa com base na classificação da Coordenação de Aperfeiçoamento de Pessoal de Nível Superior (CAPES), o WebQualis ${ }^{3}$, e na análise dos objetivos da revista, expostos, em geral, no editorial de cada uma delas. Assim, dentre os periódicos dos estratos A1, A2 e B1 (maiores níveis na classificação) da área de Ensino da CAPES, foram selecionadas 16 revistas em que constatamos, por meio da leitura de seus editoriais, uma vinculação com o ensino de/educação em Ciências ${ }^{4}$ para integrarem o corpus da pesquisa. Todos os exemplares disponíveis até dezembro de 2013 no sítio eletrônico de cada periódico foram examinados, por isso, o período analisado, bem como o total de números investigados, variou de acordo com cada revista, conforme pode ser observado na Tabela 1.

Consideramos que o trabalho seja de natureza quantitativa-qualitativa, entendendo que ambos os aspectos (quantitativos e qualitativos) complementam-se aqui para a compreensão da realidade (MINAYO; SANCHES, 1993).

\section{Resultados e discussão}

\section{Caracterização geral dos artigos}

Conforme já apresentado na tabela 1, apenas 21 artigos (distribuídos em nove revistas: Ciência \& Educação, Ensaio: Pesquisa em Educação em Ciências, Investigações em Ensino de Ciências, Revista Brasileira de Pesquisa em Educação em Ciências, Caderno Brasileiro de Ensino de Física, Ciência em Tela, Genética na Escola, Química Nova na Escola, Revista Brasileira de Ensino de Ciência e Tecnologia e Revista Práxis) do total investigado apresentaram alguma vinculação entre AC/LC e leitura/ escrita $^{5}$. No Quadro 1, apresentamos a lista dos 21 artigos, com seus títulos, autores, ano e periódico de publicação. Dos 21 artigos, apenas dois pertencem a um mesmo número de revista (n. 10 de 2013 da revista Práxis). Portanto, dos 506 números investigados, somente vinte apresentaram trabalhos relacionados à leitura e/ou escrita

\footnotetext{
${ }^{3}$ Disponível em: < http:/ qualis.capes.gov.br/webqualis/principal.seam>. Acesso em: 10 out. 2013.

${ }^{4}$ A presença de termos como "Ensino de Ciências", "Ensino/Aprendizagem de Ciências", "Ensino das Ciências da Natureza", "Ensino de Química", "Ensino de Física", "Educação em Ciência(s)", foi o principal indicador explícito de tal vinculação. Em alguns casos, no entanto, mesmo sem a presença de tais termos, a vinculação com o Ensino de/Educação em Ciências foi considerada implícita no texto dos objetivos da revista. Como exemplo, trazemos o caso da revista Ciência em Tela, que traz, em seu sítio eletrônico, as seguintes informações a respeito da publicação: "A revista recebe submissões [...] valorizando a participação de professores da escola básica e do ensino superior, educadores que atuam em espaços não formais, cientistas, pesquisadores em ensino e divulgadores de ciência" (Disponível em: <http://www.cienciaemtela.nutes.ufrj.br/index.html>. Acesso em 10 out. 2013. Grifo nosso).

${ }^{5}$ Para mais detalhes a respeito das etapas de busca e seleção dos periódicos, ver Ferreira e Galieta (2014).
} 
Tabela 1. Periódicos investigados, organizados segundo classificação Qualis da CAPES, com respectivos períodos e quantidade de números investigados.

\begin{tabular}{|c|c|c|c|c|}
\hline $\begin{array}{l}\text { Qualis } \\
\text { CAPES }\end{array}$ & Periódicos & Período & $\begin{array}{c}\text { Total de } \\
\text { números } \\
\text { investigados }\end{array}$ & $\begin{array}{c}\text { Total de } \\
\text { artigos } \\
\text { encontrados }\end{array}$ \\
\hline \multirow[t]{2}{*}{ A1 } & Ciência \& Educação & $1998-2013$ & 43 & 6 \\
\hline & Revista Brasileira de Ensino de Física (RBEF) & $2001-2013$ & 51 & 0 \\
\hline \multirow[t]{3}{*}{ A2 } & Ensaio: Pesquisa em Educação em Ciências & $1999-2013$ & 34 & 1 \\
\hline & Investigações em Ensino de Ciências (IENCI) & $1996-2013$ & 54 & 3 \\
\hline & $\begin{array}{l}\text { Revista Brasileira de Pesquisa em Educação em } \\
\text { Ciências (RBPEC) }\end{array}$ & $2001-2013$ & 38 & 2 \\
\hline \multirow[t]{12}{*}{ B1 } & Alexandria - UFSC & $2008-2013$ & 17 & 0 \\
\hline & Caderno Brasileiro de Ensino de Física (CBEF) & $1984-2013$ & 96 & 2 \\
\hline & Ciência em Tela & 2008-2012 & 9 & 1 \\
\hline & Ciência \& Ensino & $1996-2008$ & 17 & 0 \\
\hline & $\begin{array}{l}\text { Experiências em Ensino de Ciências - UFRGS } \\
\text { (EENCI) }\end{array}$ & $2006-2013$ & 24 & 0 \\
\hline & Genética na Escola & $2006-2013$ & 16 & 1 \\
\hline & Química Nova na Escola & $1995-2013$ & 50 & 2 \\
\hline & $\begin{array}{l}\text { Revista Brasileira de Ensino de Bioquímica e } \\
\text { Biologia Molecular (RBEBBM) }\end{array}$ & 2001-2012 & 19 & 0 \\
\hline & $\begin{array}{l}\text { Revista Brasileira de Ensino de Ciência e } \\
\text { Tecnologia (RBECT) }\end{array}$ & $2008-2013$ & 18 & 1 \\
\hline & Revista Ciências \& Ideias & $2009-2013$ & 6 & 0 \\
\hline & Revista Práxis & $2009-2013$ & 14 & 2 \\
\hline & Total & & 506 & 21 \\
\hline
\end{tabular}

Fonte: Elaborada pelas autoras.

e AC/LC, ou seja, apenas 3,9\% dos números. Por meio da leitura completa de cada um destes 21 artigos, verificamos uma heterogeneidade de temáticas de pesquisa (divulgação científica para o Ensino Fundamental; concepções de professores sobre o ensino de ciências; natureza da ciência; ensino de ciências e/ou de química, física, biologia; tomada de decisão; currículo e enfoque CTS; contextualização e problematização na concepção freireana; Tecnologias da Informação e da Comunicação - TIC; linguagem, leitura e escrita em ciências; filosofia e história da ciência; popularização da ciência; educação para a cidadania; formação continuada de professores; e interações discursivas) que se refletiu na diversidade de abordagens metodológicas e de referenciais teóricos utilizados.

Concluímos que, apesar dessa variedade de teorias que sustentam as discussões propostas nestes artigos, poucos (três) são os artigos que aprofundam ou problematizam, de alguma maneira, os possíveis conceitos de AC/LC, o que pode indicar que determinados sentidos, para a AC/LC, já estão "naturalizados" entre a comunidade de pesquisadores de Ensino de Ciências (EC); e que, agora, a preocupação não é mais "destrinchar" o conceito em si, mas refletir e investigar o conceito em ação. Tais sentidos "naturalizados" confundem-se com a própria 
função do EC, que, nesse contexto, seria a de alfabetizar/letrar cientificamente, o que estaria relacionado à formação de um cidadão participativo nas tomadas de decisão referentes a temas científicos e tecnológicos na sua vida cotidiana e/ou na sociedade de forma geral. No entanto, o sentido de cidadania, que tipos de decisões e como essa participação se daria, não são, em geral, debatidos ou questionados.

Por outro lado, por meio da análise da diversidade de abordagens metodológicas e de referenciais utilizados, percebemos que a comunidade acadêmica vem se utilizando de diferentes perspectivas oriundas de áreas de conhecimento específicas - como a Linguística, a Sociologia e a Psicologia - para delinear o conceito de AC/LC de modo que estes conceitos sejam (re) pensados e (re)contextualizados no EC de acordo com um olhar multidisciplinar.

Quadro 1. Lista dos artigos encontrados.

\begin{tabular}{|l|c|c|}
\hline \multicolumn{1}{|c|}{ Título do artigo } & Autor, ano & Periódico \\
\hline Alfabetização científica: questões para reflexão & TEIXEIRA, 2013 & C\&E \\
\hline $\begin{array}{l}\text { Contribuições de um encontro juvenil para a enculturação } \\
\text { científica }\end{array}$ & FEJES et al., 2012 & C\&E \\
\hline $\begin{array}{l}\text { Ensino de ciências no fundamental 1: perfil de um grupo } \\
\text { de professores em formação continuada num contexto de } \\
\text { alfabetização científica }\end{array}$ & $\begin{array}{c}\text { NIGRO; AZEVEDO, } \\
\text { 2011 }\end{array}$ & C\&E \\
\hline $\begin{array}{l}\text { O papel da natureza da ciência na educação para a cidadania } \\
\text { PRAIA; GIL-PEREZ; } \\
\text { VILCHES, 2007 }\end{array}$ & C\&E \\
\hline $\begin{array}{l}\text { A alfabetização científica e o processo de ler e escrever em } \\
\text { séries iniciais: emergências de um estudo de investigação-ação }\end{array}$ & $\begin{array}{c}\text { BRANDI; GURGEL, } \\
\text { 2002 }\end{array}$ & C\&E \\
\hline $\begin{array}{l}\text { Tomada de decisão para ação social responsável no ensino de } \\
\text { ciências }\end{array}$ & $\begin{array}{c}\text { SANTOS; } \\
\text { MORTIMER, 2001 }\end{array}$ & C\&E \\
\hline $\begin{array}{l}\text { Iniciação à alfabetização científica nos anos iniciais: } \\
\text { contribuições de uma sequência didática }\end{array}$ & $\begin{array}{c}\text { VIECHENESKI; } \\
\text { CARLETTO, 2013 }\end{array}$ & IENCI \\
\hline $\begin{array}{l}\text { O ensino de ciências nos anos iniciais do ensino fundamental } \\
\text { sob a ótica CTS: uma proposta de trabalho diante dos } \\
\text { artefatos tecnológicos que norteiam o cotidiano dos alunos }\end{array}$ & $\begin{array}{c}\text { FABRI; SILVEIRA, } \\
\text { 2013 }\end{array}$ & IENCI \\
\hline $\begin{array}{l}\text { Alfabetização científica: uma revisão bibliográfica } \\
\text { CARVALHO, 2011 }\end{array}$ & IENCI \\
\hline
\end{tabular}


Quadro 1. continuação

\begin{tabular}{|c|c|c|}
\hline Título do artigo & Autor, ano & Periódico \\
\hline $\begin{array}{l}\text { Contextualização do ensino de química pela problematização } \\
\text { e alfabetização científica e tecnológica: uma possibilidade para } \\
\text { a formação continuada de professores }\end{array}$ & $\begin{array}{l}\text { AIRES; LAMBACH, } \\
2010\end{array}$ & RBPEC \\
\hline $\begin{array}{l}\text { Leitura, discussão e produção de textos como recurso } \\
\text { didático para o ensino de biologia }\end{array}$ & $\begin{array}{l}\text { SOARES; } \\
\text { COUTINHO, } 2009\end{array}$ & RBPEC \\
\hline $\begin{array}{l}\text { Ensino de física mediado por tecnologias digitais de } \\
\text { informação e comunicação e a literacia científica }\end{array}$ & $\begin{array}{l}\text { RANGEL; SANTOS; } \\
\quad \text { RIBEIRO, } 2012\end{array}$ & CBEF \\
\hline Popularização da ciência: uma revisão conceitual & $\begin{array}{l}\text { GERMANO; } \\
\text { KULESZA, } 2007\end{array}$ & $\mathrm{CBEF}$ \\
\hline A química disciplinar em ciências do $9^{\circ}$ ano & $\begin{array}{l}\text { MILARÉ; ALVES } \\
\text { FILHO, } 2010\end{array}$ & QNEscola \\
\hline Educação em ciências, letramento e cidadania & PAULA; LIMA, 2007 & QNEscola \\
\hline Alfabetização científica no contexto das séries iniciais & $\begin{array}{l}\text { LORENZETTI; } \\
\text { DELIZOICOV, } 2001\end{array}$ & Ensaio \\
\hline $\begin{array}{l}\text { Comunicação em museus: uma oficina de elaboração de } \\
\text { etiquetas }\end{array}$ & $\begin{array}{l}\text { CARBONESE et al., } \\
2011\end{array}$ & $\begin{array}{l}\text { Ciência em } \\
\text { Tela }\end{array}$ \\
\hline $\begin{array}{l}\text { A linguagem e a alfabetização científicas: características } \\
\text { linguísticas e argumentativas de artigos científicos }\end{array}$ & $\begin{array}{l}\text { SCARPA; } \\
\text { TRIVELATO, } 2012\end{array}$ & $\begin{array}{l}\text { Genética } \\
\text { na Escola }\end{array}$ \\
\hline $\begin{array}{l}\text { Alfabetização científica e tecnológica nos anos iniciais a partir } \\
\text { do tema lixo tecnológico }\end{array}$ & $\begin{array}{l}\text { FABRI; SILVEIRA, } \\
2012\end{array}$ & RBECT \\
\hline $\begin{array}{l}\text { As mídias como ferramenta pedagógica para o ensino de } \\
\text { ciências: uma experiência na formação de professores de nível } \\
\text { médio }\end{array}$ & $\begin{array}{l}\text { DIÓRIO; RÔÇAS, } \\
2013\end{array}$ & Práxis \\
\hline $\begin{array}{l}\text { Alfabetização científica: apropriações discursivas no } \\
\text { desenvolvimento da escrita de alunos em aula de ecologia }\end{array}$ & $\begin{array}{l}\text { YAMADA; } \\
\text { MOTOKANE, } 2013\end{array}$ & Práxis \\
\hline
\end{tabular}

C\&E: Ciência \& Educação; IENCI: Investigações em Ensino de Ciências; RBPEC: Revista Brasileira de Pesquisa em Educação em Ciências; CBEF: Caderno Brasileiro de Ensino de Física; QNEscola: Química Nova na Escola. Fonte: Elaborado pelas autoras. 
No presente trabalho, podemos destacar outros aspectos ainda não explorados dos 21 artigos resultantes do levantamento que corroboram o caráter heterogêneo e diversificado das pesquisas que lançam mão do(s) termo(s) AC/LC. Ao analisarmos a natureza das investigações realizadas, por exemplo, verificamos que há um relativo equilíbrio entre trabalhos empíricos (13) e teóricos (8), sendo que os trabalhos empíricos apresentam diversificados objetos de estudo: objetos virtuais de aprendizagem e/ou mídias no ensino (AIRES; LAMBACH, 2010; DIÓRIO; RÔÇAS, 2013;); a alfabetização científica nas séries iniciais do EF (BRANDI; GURGEL, 2002; FABRI; SILVEIRA, 2012, 2013; NIGRO; AZEVEDO, 2011; VIECHENESKI; CARLETTO, 2013); argumentação em artigos originais de cientistas (SCARPA; TRIVELATO, 2012); leitura e/ou escrita (SOARES; COUTINHO, 2009; YAMADA; MOTOKANE, 2013); divulgação científica como ação didático-pedagógica (CARBONESE et al., 20116; FEJES et al., 2012); abordagem dos conteúdos de química no $9^{\circ}$ ano (MILARÉ; ALVES FILHO, 2010). Os trabalhos teóricos, por sua vez, apresentam revisões de literatura e discussões sobre: o conceito de alfabetização científica e/ou letramento (PAULA; LIMA, 2007; SASSERON; CARVALHO, 2011); o conceito de popularização da ciência (GERMANO; KULESZA, 2007); a alfabetização científica nas séries iniciais (LORENZETTI; DELIZOICOV, 2001); a tomada de decisão no ensino de ciências (SANTOS; MORTIMER, 2001); alfabetização científica e a escrita/leitura (RANGEL; SANTOS; RIBEIRO, 2012; TEIXEIRA, 2013); o papel da natureza da ciência na educação científica (PRAIA; GIL-PEREZ; VILCHES, 2007) e uso das TIC's no ensino de Física/Ciências (RANGEL; SANTOS; RIBEIRO, 2012).

Tal heterogeneidade, no entanto, não se faz tão presente se observarmos que, dentre os trabalhos empíricos, quase todos se constituem no âmbito da educação formal - cinco no segmento inicial do Ensino Fundamental (EF), três no segmento final, dois no Ensino Médio e três ${ }^{7}$ na formação (inicial ou continuada) de professores - e apenas um no âmbito da educação não formal (museu). Entre os artigos teóricos, encontramos dois que se dedicam à discussão voltada para segmentos específicos do ensino - um do ensino de física e outro dos anos iniciais do Ensino Fundamental. Podemos afirmar, portanto, que há uma maior preocupação com o ensino de Ciências no Ensino Fundamental, sobretudo nas séries iniciais, nos artigos que tratam de AC/LC e leitura/escrita. Esse foco nas séries iniciais pode estar relacionado à gênese do conceito de AC, na qual o termo alfabetização é apropriado do campo da linguagem e, nele, indica o contexto de alfabetização na língua materna. Nesse sentido, os autores desses artigos, nos quais o foco é o segmento inicial do EF (BRANDI; GURGEL, 2002; FABRI; SILVEIRA, 2012, 2013; GERMANO; KULESZA, 2007; LORENZETTI; DELIZOICOV, 2001; VIECHENESKI;

\footnotetext{
${ }^{6}$ Este artigo tem como base uma adaptação de oficina de comunicação em museus, e foi realizada em uma exposição promovida pelo Centro de Capacitação e Pesquisa em Meio Ambiente (CEPEMA) da Universidade de São Paulo (USP). Por isso, foi incluído, anteriormente, na categoria de trabalho empírico no contexto da educação não formal, mas vale frisar que o público-alvo da exposição também era o público escolar, assim como a maioria dos trabalhos empíricos.

${ }^{7} \mathrm{Um}$ dos trabalhos trata do perfil de um grupo de professores em formação continuada no contexto do ensino de ciências, no primeiro segmento do EF, e, por isso, foi incluído nas duas categorias: segmento inicial do EF e formação inicial/continuada de professores.
} 
CARLETTO, 2013), podem estar valorizando a AC/LC nessas séries porque é nelas que se inicia a alfabetização na língua, e, da mesma forma, deveria se iniciar a alfabetização científica. Veremos mais adiante, no entanto, que a AC/LC da qual falam esses autores está preocupada com aspectos tais como: compreensão da natureza da Ciência e a resolução de problemas no dia a dia, e não com a discussão das especificidades da leitura/escrita nas Ciências.

$\mathrm{Na}$ seção a seguir, aprofundaremos a discussão a respeito das relações estabelecidas com leitura/escrita nos trabalhos que abordam AC/LC resultantes do levantamento.

\section{Relações entre leitura/escrita e AC/LC}

Apesar de todos os 21 artigos apresentarem, de alguma forma, a questão da leitura e escrita, em apenas três deles a relação entre leitura/escrita e AC/LC aparece como problemática principal (SOARES; COUTINHO, 2009; TEIXEIRA, 2013; YAMADA; MOTOKANE, 2013).

Em um deles, Teixeira (2013) realiza uma reflexão sobre os significados atribuídos à expressão alfabetização científica, retomando a origem histórica dos termos alfabetização e letramento e seus respectivos significados na área de linguagem. Analisa, então, a apropriação desses termos no âmbito do ensino de Ciências e argumenta que a alfabetização científica diz respeito a tudo aquilo que envolve leitura e escrita de texto científico. No artigo de Yamada e Motokane (2013), por sua vez, os autores buscam entender o desenvolvimento da escrita de alunos do $6^{\circ}$ ano em uma aula de Ecologia, considerando que a constituição das habilidades de leitura e de escrita representa um ponto importante para o processo de alfabetização científica. Já Soares e Coutinho (2013), em seu artigo "Leitura, discussão e produção de textos como recurso didático para a biologia", apresentam a análise de uma atividade de leitura e escrita planejada segundo abordagem sociocultural e avaliada de acordo com abordagem psicológica sociointeracionista do discurso, realizada no Ensino Médio para o ensino de biologia, argumentando que a atividade proposta por eles contribuiria para o letramento científico. Em uma das seções do texto, intitulada "A Linguagem Científica e o Letramento Científico", os autores defendem que a linguagem científica possui recursos lexicogramaticais específicos da área, e que o letramento científico estaria, então, relacionado à habilidade de decodificar essa linguagem específica, fazendo com que o indivíduo seja capaz de conversar, ler e escrever significativamente no contexto científico. Por outro lado, o letramento científico, para esses autores, refere-se, também, ao desenvolvimento de hábitos mentais científicos, tais como: o raciocínio lógico, o entendimento do papel da experiência e a confiança na evidência.

Em outro dos 21 artigos investigados (SCARPA; TRIVELATO, 2012), apesar de verificarmos a presença clara do componente leitura/escrita-AC/LC, o foco não está voltado especificamente para essa questão, mas para a natureza da argumentação nas Ciências. Ainda assim, os autores demonstram interesse na relação entre linguagem e alfabetização e, logo no início do trabalho, estabelecem vínculos explícitos entre alfabetização científica e leitura e escrita:

O ensino por investigação e a ênfase nos processos de leitura e escrita de textos científicos têm recebido atenção nas pesquisas em ensino de ciências cujo foco está na alfabetização científica. Norris e Phillips (2003) defendem que [...] ler e escrever são habilidades necessárias para o acesso dos estudantes de educação básica a um determinado 'fazer 
científico'. [...] Logo no início de seu artigo, Phillips e Norris (2009, p. 313) defendem uma posição da qual compartilhamos: "Quando cientistas leem, eles estão realizando investigações.” Em contraposição à caracterização das ciências experimentais como fundamentalmente baseadas em atividades hands-on, os autores apresentam dados que sustentam que, na maior parte do tempo, os cientistas estão envolvidos em atividades minds-on-leitura, escrita e/ou fala. Por esse motivo, é importante que os currículos e os professores de ciências deem a devida importância para a leitura em ciências e que a concepção de leitura como investigação esteja presente de forma mais intensa na educação científica. (SCARPA; TRIVELATO, 2012, p. 47. Grifos dos autores)

Aliás, entendemos que os estudos de Norris e Phillips (2003) são de grande relevância para a discussão do tema objeto de nosso trabalho, visto que são utilizados no estabelecimento de relações entre leitura-escrita-AC/LC em outros artigos de nosso levantamento: no trabalho já citado de Teixeira (2013) e nos textos de Nigro e Azevedo (2011), Paula e Lima (2007) e Sasseron e Carvalho (2011). No trabalho de Sasseron e Carvalho, é realizada uma revisão bibliográfica sobre AC. Nele discute-se a dificuldade em definir o termo, pela amplitude e controvérsia do mesmo, e diversos aspectos da AC/LC são abordados, dentre eles, o "sentido fundamental" de Norris e Phillips (2003), bem como a "dimensão funcional" de Bybee (1995 apud SASSERON; CARVALHO, 2011, p. 63). O domínio da escrita e da leitura só aparece novamente no trabalho de Sasseron e Carvalho (2011) quando uma citação de Paulo Freire (1980 apud SASSERON; CARVALHO, 2011, p. 61) sobre alfabetização é utilizada no sentido de alicerçar as bases da expressão "alfabetização científica” na perspectiva das autoras: “[...] a alfabetização é mais que o simples domínio psicológico e mecânico de técnicas de escrever e de ler. É o domínio destas técnicas em termos conscientes. [...] Implica numa autoformação de que possa resultar uma postura interferente do homem sobre seu contexto".

No artigo de Paula e Lima (2007), os diversos significados atribuídos ao conceito de letramento são discutidos e, nesse sentido, o trabalho de Norris e Phillips (2003) e seu "sentido fundamental" da leitura e da escrita nas Ciências são novamente citados. No entanto, a problemática do artigo não está voltada para essa questão, e sim, para a defendida impertinência do uso do termo letramento científico (e para a preferência pelo termo alfabetização científica). Os autores têm a intenção de, com essa discussão, "resgatar pontos de vista e abordagens da educação em ciências comprometidas com a formação de sujeitos aptos a reivindicar e a exercer a cidadania" (PAULA; LIMA, 2007, p. 3).

Entendemos que Soares e Coutinho (2009), por sua vez (que, conforme vimos, apresentam um trabalho cuja problemática principal está voltada para a relação leitura-escrita-AC/

\footnotetext{
${ }^{8} \mathrm{O}$ "sentido fundamental" da AC, atribuído por Norris e Philips (2003), foi apresentado na introdução deste artigo. Já a "dimensão funcional” da AC, proposta por Bybee (1995 apud ROBERTS, 2007, p. 741; SASSERON; CARVALHO, 2011, p. 63), refere-se ao nível de AC no qual os indivíduos utilizam adequadamente o vocabulário científico simples, realizando associações com esquemas conceituais mais amplos, mas têm um entendimento ainda simbólico dessas associações.
} 
LC), consideram a leitura e escrita em Ciências na AC/LC em seu "sentido fundamental", como proposto por Norris e Philips (2003), apesar de não os citarem, quando explicam que:

A leitura e a discussão dos fragmentos de artigos científicos e a produção da resenha acadêmica, ambas compreendidas como ações de linguagem, foram utilizadas como ferramentas no desenvolvimento do Letramento Científico, ou seja, no desenvolvimento da competência dos alunos nesta área específica, a das Ciências Naturais. Os fragmentos foram escolhidos pela possibilidade de colocar o aluno em contato com o gênero predominante utilizado pelas Ciências Naturais e a resenha acadêmica por demandar uma série de habilidades que dessem pistas sobre o entendimento destes fragmentos pelos alunos. (SOARES; COUTINHO, 2009, p. 5)

O trabalho de Nigro e Azevedo (2011) também faz referência a Norris e Phillips (2003), mas a preocupação com a associação leitura-escrita-AC/LC aparece apenas nas considerações finais do trabalho, no qual o perfil de um grupo de professores do primeiro segmento do Ensino Fundamental, participantes de um projeto de formação continuada que tinha como objetivo promover a alfabetização científica, é apresentado. Ao analisarem quais os objetivos atribuídos ao ensino de Ciências por esses professores, os autores Nigro e Azevedo (2011, p. 6) destacaram que

[...] objetivos relacionados à comunicação (leitura-escrita) foram frequentemente citados pelos professores, porém, aparentemente, de maneira que sugere que estes objetivos relacionam-se mais às demandas genéricas de ensino de línguas, permeando outras disciplinas escolares, do que a um real reconhecimento do papel da linguagem para o desenvolvimento do conhecimento científico - e, assim, a uma possível conotação de alfabetização científica em seu sentido mais fundamental, segundo a definição de Norris e Phillips (2003).

Aqui podemos refletir sobre a conclusão desses autores e sua relação com boa parte dos trabalhos analisados que está voltada para o ensino de ciências nas séries iniciais (BRANDI; GURGEL, 2002; FABRI; SILVEIRA, 2012, 2013; GERMANO; KULESZA, 2007; LORENZETTI; DELIZOICOV, 2001; VIECHENESKI; CARLETTO, 2013).

No artigo de Brandi e Gurgel (2002), apesar do foco ser a questão da AC nas séries iniciais, em processo de alfabetização na língua materna, e, por isso, apresentar uma preocupação com a questão da linguagem, a associação entre a linguagem e a AC/LC não aparece de forma muito clara, mas pode ser observada implicitamente na questão norteadora do trabalho: "Como ocorre, através de uma parceria colaborativa, o redimensionamento da prática pedagógica de um professor que trabalha com a leitura e a escrita na perspectiva da alfabetização científica?” (BRANDI; GURGEL, 2002, p. 116). Presume-se que os autores entendem que atividades de leitura e escrita podem ser realizadas em uma perspectiva de AC, mas que as discussões sobre CTS são as priorizadas, e não a questão da linguagem nas Ciências como uma dimensão intrínseca 
à AC/LC. A ideia defendida pelos autores é fazer uso das Ciências para que os alunos possam aprender a ler e a escrever na língua materna, que seria o objetivo final das séries iniciais, e, ao realizarem essas práticas, os alunos seriam alfabetizados cientificamente.

Lorenzetti e Delizoicov (2001), ao defenderem a AC nas séries iniciais, apresentam diversas definições da literatura para este termo; uma delas menciona a leitura: "capacidade de ler, compreender e expressar opinião sobre assuntos de caráter científico" (MILLER, 1983, p. 30 apud LORENZETTI; DELIZOICOV, 2001, p. 39). Mais adiante, os autores apresentam as dimensões da alfabetização científica de Bybee (1995 apud LORENZETTTI DELIZOICOV, 2001, p. 39), também utilizadas por Sasseron e Carvalho (2011): "funcional", "conceitual e processual" e "multidimensional". A respeito da primeira afirmam que:

[...] objetiva o desenvolvimento de conceitos, centrando-se na aquisição de um vocabulário, palavras técnicas, envolvendo a Ciência e a Tecnologia. [...] Assim, "de acordo com a idade dos educandos, fase de desenvolvimento, e o nivel de educação, os estudantes deveriam estar aptos a ler e escrever passagens que incluem vocabulário científico e tecnológico" (Bybee, 1995: 29). Este autor argumenta que os professores têm dado na sua prática docente [...] uma ênfase muito grande para esta dimensão da alfabetização científica, considerando que para desenvolver a alfabetização científica seja necessário atingir um grande número de conceitos, possuindo um amplo vocabulário científico. (LORENZETTI; DELIZOICOV, 2011, p. 41-42. Grifo dos autores)

Os autores, portanto, reconhecem a importância de ler e escrever no contexto científico, mas priorizam outros aspectos da AC/LC, tais como a compreensão da natureza da Ciência e a resolução de problemas no dia a dia. O artigo de Lorenzetti e Delizoicov (2001) é utilizado como referencial em outros textos (FABRI; SILVEIRA, 2012, 2013; GERMANO; KULESZA, 2007) que defendem a AC nas séries iniciais, sendo uma mesma passagem citada ou referenciada nos três, a saber:

A definição de alfabetização científica como a capacidade do indivíduo ler, compreender e expressar opinião sobre assuntos que envolvam a Ciência, parte do pressuposto de que o indivíduo já tenha interagido com a educação formal, dominando, desta forma, o código escrito. Entretanto, complementarmente a esta definição, e num certo sentido a ela se contrapondo, partimos da premissa de que é possível desenvolver uma alfabetização científica nas Séries Iniciais do Ensino Fundamental, mesmo antes do aluno dominar o código escrito. (LORENZETTI; DELIZOICOV, 2001, p. 39)

Nesse sentido, podemos fazer distinção entre uma perspectiva de relação entre a aprendizagem de Ciências $e$ de leitura/escrita na língua materna, como aquela apontada por Nigro e Azevedo (2011) ao analisar os objetivos atribuídos ao ensino de Ciências pelos professores, que é também verificada nos artigos que tratam da $\mathrm{AC} / \mathrm{LC}$ nas séries iniciais, e outra 
perspectiva, na qual os autores consideram em suas argumentações a questão da especificidade da aprendizagem da leitura e da escrita nas Ciências, que foi observada em apenas quatro dos artigos analisados (SCARPA; TRIVELATO, 2012; SOARES; COUTINHO, 2009; TEIXEIRA, 2013; YAMADA; MOTOKANE, 2013).

Nas demais publicações resultantes do levantamento (AIRES; LAMBACH, 2010; CARBONESE et al., 2011; DIÓRIO; RÔÇAS, 2013; FEJES et al., 2012; MILARÉ; ALVES FILHO, 2010; PRAIA; GIL-PEREZ; VILCHES, 2007; RANGEL; SANTOS; RIBEIRO, 2012; SANTOS, MORTIMER, 2001), assim como em algumas das já citadas (NIGRO; AZEVEDO, 2011; PAULA; LIMA, 2007), a relação entre as duas perspectivas pesquisadas (AC/LC - leitura/ escrita) aparece apenas superficialmente, em geral, na apresentação de conceitos e definições para AC/LC. No artigo de Santos e Mortimer (2001), por exemplo, o letramento científico e tecnológico (LCT) é apresentado como principal objetivo do currículo CTS, e os autores têm como foco os aspectos sociocientíficos da AC/LC. No entanto, em nota de rodapé, é apresentada a seguinte definição para LCT: "letramento científico e tecnológico seria a condição de quem não apenas reconhece a linguagem científica e tecnológica, mas cultiva e exerce práticas sociais que usam tal linguagem" (SANTOS; MORTIMER, 2001, p. 96). Entendemos, dessa forma, que, para estes autores, apesar de não ser dada maior atenção à leitura/escrita em suas discussões (dado que a questão aparece apenas em uma nota de rodapé), saber ler e escrever a linguagem da Ciência é condição essencial para que o indivíduo seja considerado letrado científica e tecnologicamente.

A relação entre AC/LC e leitura/escrita, inclusive, nem sempre aparece de forma explícita, como no artigo de Praia, Gil-Perez e Vilches (2007) sobre o papel da natureza da Ciência na educação para cidadania. Nele, a AC é abordada levando em consideração aspectos da natureza da Ciência, mas sem propriamente abranger a questão da linguagem científica e da leitura/escrita. No entanto, quando os autores propõem o planejamento da aprendizagem por meio do "tratamento de situações problemáticas" relevantes, com inclusão de uma série de aspectos, dentre eles, a análise e comunicação dos resultados, afirmam que: "É preciso chamar a atenção sobre a importância da comunicação como substracto da dimensão colectiva do trabalho científico e tecnológico. Isso supõe que os estudantes se familiarizem com a leitura e construção de memórias científicas e trabalhos de divulgação" (PRAIA, GIL-PEREZ; VILCHES, 2007, p. 151).

Dessa forma, a relação da leitura/escrita com o conceito de AC/LC não é diretamente estabelecida, mas fica implícita ao reconhecer a importância do saber ler e escrever no contexto de construção de um saber científico.

Mesmo reconhecendo que todos os 21 artigos analisados apresentam alguma relação entre leitura-escrita-AC/LC, verificamos que a maior parte deles (18), ao abordar a/o AC/LC, foca em questões como: a compreensão de conceitos científicos, aspectos da natureza e da história e filosofia da ciência, controvérsias sociocientíficas, relações CTS, desenvolvimento de autonomia, formação cidadã e/ou tomada de decisão. Dessa forma, apesar da estreita relação entre os conceitos de AC/LC e os processos de leitura/escrita, já abordada na introdução deste trabalho, quando se fala em AC/LC, nos artigos analisados, a leitura/escrita não se apresenta como foco na maior parte deles.

Ainda assim, dos 21 artigos, oito são trabalhos empíricos em que algum tipo de produção escrita de alunos foi objeto de análise ou fez parte de atividades de sequências didáticas 
realizadas. Diório e Rôças (2013) realizaram, num ciclo de oficinas com professores de nível médio em formação, uma atividade na qual a proposta era adaptar artigos científicos da revista Química Nova, na escola, para alunos do EF, mas os dados que constituíram objeto de análise da pesquisa foram gerados em um questionário no último encontro com o grupo. No trabalho de Carbonese et al. (2011), alunos do segundo segmento do EF participaram de uma oficina de elaboração de etiquetas de animais taxidermizados em um museu. Fejes et al. (2012) analisaram textos dissertativos produzidos por grupos de alunos, também do segundo segmento do EF, em uma atividade de avaliação dos projetos realizados em suas escolas. Fabri e Silveira (2012, 2013) realizaram sequências didáticas com alunos do $5^{\circ}$ ano (primeiro segmento do EF), que incluíram: questionários de concepções prévias e sobre textos ou vídeos trabalhados em aula, confecção de folders, acrósticos, finalização de texto narrativo, relato sobre visitas ou entrevistas realizadas, e construção coletiva de protocolo de entrevistas. Viecheneski e Carletto (2013) analisaram uma sequência didática realizada com alunos do $1^{\circ}$ ano (primeiro segmento do EF), na qual ocorreu a construção coletiva de protocolos de entrevistas e a produção (também de forma coletiva) de pequeno texto dissertativo sobre assunto da sequência. Soares e Coutinho (2009) analisaram resenhas acadêmicas de fragmentos de artigos científicos produzidas por alunos do $1^{\circ}$ ano do Ensino Médio antes e depois de uma atividade de discussão. E, finalmente, Yamada e Motokane (2013) elaboraram uma sequência didática com objetivo de trabalhar os aspectos de elaboração de hipóteses e previsões na Ciência, bem como da interpretação de dados com alunos do $6^{\circ}$ ano (segundo segmento do EF), e as atividades da sequência que envolveram escrita foram, basicamente, diferentes tipos de questionários.

Ao encontrarmos pesquisas, como as relatadas nos artigos supracitados, nas quais a escrita e/ou a leitura são objetos empíricos, percebemos a existência de um possível pressuposto implícito a elas, a saber: a habilidade de ler/escrever quando o conteúdo é científico difere da habilidade de ler/escrever outros temas, o que estaria relacionado a determinados gêneros textuais que são privilegiados no âmbito do ensino das ciências, tais como: roteiros e relatórios de atividades prático-experimentais e artigos científicos. Indo além, notamos que alguns autores, tais como Diório e Rôças (2013) e Fejes et al. (2012), relacionam tais habilidades ao conceito de LC, de modo que estaria sendo privilegiado o sentido fundamental do LC, de acordo com Norris e Phillips (2003).

\section{Considerações finais}

Neste trabalho, analisamos as relações estabelecidas com leitura/escrita em 21 artigos resultantes de um levantamento bibliográfico que abordam a questão dentro de uma perspectiva de AC/LC. Apesar de os artigos tratarem dos processos de leitura e escrita no Ensino de Ciências como uma dimensão da AC/LC, essa relação aparece como objeto de estudo em apenas três artigos, o que nos permite afirmar que tal questão ainda é muito pouco investigada no Brasil pelos pesquisadores da área de Educação em Ciências.

Muitas das publicações que consideram o papel da escrita/leitura no Ensino de Ciências e fazem referência à $\mathrm{AC} / \mathrm{LC}$, estabelecem vínculos superficiais entre essas duas perspectivas (AC/ LC - leitura/escrita), ou consideram apenas a associação entre a aprendizagem de Ciências $e$ de leitura/escrita na língua materna, e não a questão da especificidade da aprendizagem da leitura 
e da escrita nas Ciências. Nesse sentido, entendemos que as pesquisas (empíricas e teóricas) que têm estes objetos de estudo deveriam ser mais rigorosas tanto no delineamento de seus referenciais teóricos quanto na adesão aos conceitos de AC ou LC, pois entendemos que, apesar de seus autores estarem atentos à questão da leitura e da escrita em aulas de Ciências, estas podem deixar de contribuir efetivamente para a compreensão de suas relações mais amplas visando à melhoria do ensino de Ciências. Por outro lado, a análise dos trabalhos em que a escrita e/ou a leitura são objetos empíricos, revela a possível existência do pressuposto implícito de que a habilidade de ler/escrever quando o conteúdo é científico difere da habilidade de ler/escrever outros temas e que isso estaria relacionado à preferência por determinados gêneros textuais no âmbito do ensino das Ciências.

Cabe ressaltar que, em nossas pesquisas, assim como Santos (2007), adotamos o termo letramento científico no sentido de enfatizar uma preocupação: com aspectos sociais da ciência, com o conhecimento científico em uso, com uma educação científica humanística, que almeja a transformação da realidade social, e não apenas a reprodução dela, mas reconhecemos que outros autores, tais como Auler e Delizoicov (2001) e Chassot (2003), utilizam o termo alfabetização científica sob uma perspectiva social e crítica. Não podemos deixar de mencionar, no entanto, que nos artigos que fizeram parte do levantamento bibliográfico, os termos AC/LC são, por vezes, utilizados com intenção explícita e teórica de demarcar diferenças (PAULA; LIMA, 2007; SANTOS, 2007), mas, em geral, seus conceitos não são teoricamente problematizados.

Abranger esse levantamento para publicações em anais de eventos da área parece-nos um caminho interessante para corroborar os resultados e discussões apresentados nesta revisão. Consideramos que pesquisas desta natureza permitem ampliar o debate sobre a promoção do letramento científico, explorando uma vertente ainda pouco analisada: o papel da leitura e da escrita na almejada formação crítica dos alunos no contexto do Ensino de Ciências.

\section{Agradecimentos}

As autoras agradecem à Coordenação de Aperfeiçoamento de Pessoal de Nível Superior (CAPES) pelo suporte financeiro, bem como aos pareceristas, pelos valiosos comentários.

\section{Referências}

AIRES, J. A.; LAMBACH, M. Contextualização do ensino de química pela problematização e alfabetização científica e tecnológica: uma possibilidade para a formação continuada de professores. Revista Brasileira de Pesquisa em Educação em Ciências, São Paulo, v. 10, n. 1, 2010. Disponível em: <http://revistas.if.usp.br/rbpec/article/view/10>. Acesso em: 29 ago. 2015.

AULER, D.; DELIZOICOV, D. Alfabetização científico-tecnológica para quê? Ensaio: pesquisa em educação em ciências, Belo Horizonte, v. 3, n. 1, p. 1-13, 2001. 
Relações entre leitura, escrita e alfabetização/letramento científico: ...

BRANDI, A. T. E.; GURGEL, C. M. A. A alfabetização científica e o processo de ler e escrever em séries iniciais: emergências de um estudo de investigação-ação. Ciência $\boldsymbol{\&}$ Educação, Bauru, v. 8, n. 1, p. 113-125, 2002. Disponível em: < http://dx.doi.org/10.1590/ S1516-73132002000100009>. Acesso em: 29 ago. 2015.

CACHAPUZ, A. et al. Do estado da arte da pesquisa em educação em ciências: linhas de pesquisa e o caso "ciência-tecnologia-sociedade". Alexandria, Florianópolis, v. 1, n. 1, p. 27-49, 2008.

CARBONESE, T. et al. Comunicação em museus: uma oficina de elaboração de etiquetas.

Ciência em Tela, Rio de Janeiro, v. 4, n. 2, p. 1-11, 2011. Disponível em: <http://www. cienciaemtela.nutes.ufrj.br/artigos/0211_carbonese.pdf>. Acesso em: 07 nov. 2013.

CHASSOT, A. Alfabetização científica: uma possibilidade para a inclusão social. Revista Brasileira de Educação, Rio de Janeiro, n. 22, p. 89-100, 2003.

DIÓRIO, A. P. I.; RÔÇAS, G. As mídias como ferramenta pedagógica para o ensino de ciências: uma experiência na formação de professores de nível médio. Revista Práxis, Volta Redonda, v. 5, n. 10, p. 56-73, 2013.

FABRI, F.; SILVEIRA, R. M. C. F. Alfabetização científica e tecnológica nos anos iniciais a partir do tema lixo tecnológico. Revista Brasileira de Ensino de Ciência e Tecnologia, Ponta Grossa, v. 5, n. 2, p. 99-127, 2012.

. O ensino de ciências nos anos iniciais do ensino fundamental sob a ótica CTS: uma proposta de trabalho diante dos artefatos tecnológicos que norteiam o cotidiano dos alunos. Investigações em Ensino de Ciências, Porto Alegre, v. 18, n. 1, p. 77-105, 2013.

FEJES, M. et al. Contribuições de um encontro juvenil para a enculturação científica. Ciência \& Educação, Bauru, v. 18, n. 4, p. 769-786, 2012. Disponível em: < http:/ /dx.doi. org/10.1590/S1516-73132012000400003>. Acesso em: 24 ago. 2015.

FERREIRA, C. S. C.; GALIETA, T. Revisão de literatura em periódicos nacionais: a produção sobre letramento científico, leitura e escrita. Revista da SBEnBio, Niteroi, v. 7, p. 1241-1252, 2014.

GERMANO, M. G.; KULESZA, W. A. Popularização da ciência: uma revisão conceitual. Caderno Brasileiro de Ensino de Física, Florianópolis, v. 24, n. 1, p. 7-25, 2007.

LORENZETTTI, L.; DELIZOICOV, D. Alfabetização científica no contexto das séries iniciais. Ensaio: pesquisa em educação em ciências, Belo Horizonte, v. 3, n. 1, p. 37-50, 2001.

MARTINS, I. Problematizando o conceito de alfabetização científica a partir de contribuições dos estudos de linguagem e letramento. In: GARCIA, N. M. D. (Org.). A pesquisa em ensino de física e a sala de aula. São Paulo: Editora da Sociedade Brasileira de Física, 2010. p. 363-389.

MILARÉ, T.; ALVES FILHO, J. P. A química disciplinar em ciências do $9^{\circ}$ ano. Química Nova na Escola, São Paulo, v. 32, n. 1, p. 43-52, 2010. Disponível em: < http://www.qnesc. sbq.org.br/online/qnesc32_1/09-PE-0909.pdf>. Acesso em: 05 jul. 2013. 
MINAYO, M. C. S.; SANCHES, O. Quantitativo-qualitativo: oposição ou complementaridade? Cadernos de Saúde Pública, Rio de Janeiro, v. 9, n. 3, p. 239-262, 1993.

MORTIMER, E. F. Sobre chamas e cristais: a linguagem cotidiana, a linguagem científica e o ensino de ciências. In: CHASSOT, A.; OLIVEIRA, R. J. (Org.). Ciência, ética e cultura na educação. São Leopoldo: Ed. Unisinos, 1998. p. 99-118.

NIGRO, R. G.; AZEVEDO, M. N. Ensino de ciências no fundamental 1: perfil de um grupo de professores em formação continuada num contexto de alfabetização científica.

Ciência \& Educação, Bauru, v. 17, n. 3, p. 705-720, 2011. Disponível em: <http:/ /dx.doi. org/10.1590/S1516-73132011000300012>. Acesso em: 24 ago. 2015.

NORRIS, S. P.; PHILIPS, L. M. How literacy in its fundamental sense is central to scientific literacy. Science Education, Hoboken, v. 87, n. 2, p. 224-240, 2003.

OLIVEIRA, O. B. de. Possibilidades da escrita no avanço do senso comum para o saber científico na $\mathbf{8}^{\mathbf{a}}$ série do ensino fundamental. 2001. 158 f. Dissertação (Mestrado em Educação) - Faculdade de Educação, Universidade Estadual de Campinas, Campinas, 2001.

PAULA, H. F.; LIMA, M. E. C. Educação em ciências, letramento e cidadania. Química Nova na Escola, São Paulo, v. 26, n. 1, p. 3-9, 2007. Disponível em: < http:/ / qnesc.sbq.org. br/online/qnesc26/v26a02.pdf>. Acesso em: 07 nov. 2013.

PRAIA, J.; GIL-PEREZ, D.; VILCHES, A. O papel da natureza da ciência na educação para a cidadania. Ciência \& Educação, Bauru, v. 13, n. 2, p. 141-156, 2007. Disponível em: <http://dx.doi.org/10.1590/S1516-73132007000200001>. Acesso em: 24 ago. 2015.

RANGEL, F. O.; SANTOS, L. S. F.; RIBEIRO, C. E. Ensino de física mediado por tecnologias digitais de informação e comunicação e a literacia científica. Caderno Brasileiro de Ensino de Física, Florianópolis, v. 29, n. 1, p. 651-677, 2012. Número especial.

ROBERTS, D. A. Scientific literacy/science literacy. In: ABEL, S. K.; LEDERMAN, N. G. (Ed.). Handbook of research on science education. Mahwah: Lawrence Erlbaum, 2007. p. $729-780$.

SANTOS, W. L. P. Educação científica na perspectiva de letramento como prática social: funções, princípios e desafios. Revista Brasileira de Educação, Rio de Janeiro, v. 12, n. 36, p. 474-550, 2007.

SANTOS, W. L. P.; MORTIMER, E. F. Tomada de decisão para ação social responsável no ensino de ciências. Ciência \& Educação, Bauru, v. 7, n. 1, p. 95-111, 2001. Disponível em: <http:/ /dx.doi.org/10.1590/S1516-73132001000100007>. Acesso em: 24 ago. 2015.

SASSERON, L. H.; CARVALHO, A. M. P. Alfabetização científica: uma revisão bibliográfica. Investigações em Ensino de Ciências, Porto Alegre, v. 16, n. 1, p. 59-77, 2011. 
SCARPA, D. L.; TRIVELATO, S. L. F. A linguagem e a alfabetização científicas: características linguísticas e argumentativas de artigos científicos. Genética na Escola, Ribeirão Preto, v. 7, n. 2, p. 46-57, 2012.

SOARES, A. D.; COUTINHO, F. A. Leitura, discussão e produção de textos como recurso didático para o ensino de biologia. Revista Brasileira de Pesquisa em Educação em Ciências, São Paulo, v. 9, n. 2, 2009.

TEIXEIRA, F. M. Alfabetização científica: questões para reflexão. Ciência \& Educação, Bauru, v. 19, n. 4, p. 795-809, 2013. Disponível em: <http://dx.doi.org/10.1590/S1516$73132013000400002>$. Acesso em: 24 ago. 2015.

. Reflexões sobre o que é alfabetização científica. In: ENCONTRO NACIONAL DE PESQUISA EM EDUCAÇÃO EM CIÊNCIAS, 8., 2011, Campinas. Atas... [S.1.]: ABRAPEC, 2011. Disponível em: <http://www.nutes.ufrj.br/abrapec/viiienpec/resumos/ R1059-1.pdf>. Acesso em: 19 ago. 2015.

TFOUNI, L. V. Adultos não alfabetizados: o avesso do avesso. 1986. 245 f. Tese (Doutorado em Ciências) - Instituto de Estudos da Linguagem, Universidade Estadual de Campinas, Campinas, 1986. Disponível em: <http://www.bibliotecadigital.unicamp.br/ document $/$ ?code $=$ vtls000051671\&fd $=\mathrm{y}>$. Acesso em: 20 nov. 2013.

TOMIO, D. Dear Mr. Charles Darwin... Dear Mr. Fritz Müller: da correspondência entre e evolucionista e o naturalista indícios para caracterizar a escrita na ciência e no ensino de ciências. In: ENCONTRO NACIONAL DE PESQUISA EM EDUCAÇÃO EM CIÊNCIAS, 7., 2009, Florianópolis. Atas... Disponível em: <http://posgrad.fae.ufmg.br/ posgrad/viienpec/pdfs/1559.pdf >. Acesso em: 17 nov. 2013.

VIECHENESKI, J. P.; CARLETTO, M. R. Iniciação à alfabetização científica nos anos iniciais: contribuições de uma sequência didática. Investigações em Ensino de Ciências, Porto Alegre, v. 18, n. 3, p. 525-543, 2013.

YAMADA, M.; MOTOKANE, M. T. Alfabetização científica: apropriações discursivas no desenvolvimento da escrita de alunos em aula de ecologia. Revista Práxis, Volta Redonda, v. 5, n. 10, p. 29-40, 2013. 